\title{
The Incidence and Mortality Impact of Gastrointestinal Bleeding in Hospitalized COVID-19 Patients
}

\author{
Jasbir Makker iD ${ }^{1,2}$ \\ Nikhitha Mantri iD \\ Harish K Patel (iD) ${ }^{1,2}$ \\ Hafsa Abbas (iD) ${ }^{1,2}$ \\ Ahmed Baiomi iD ${ }^{1,2}$ \\ Haozhe Sun (D) \\ Yongsub Choi iD \\ Sridhar Chilimuri (iD ${ }^{1,2}$ \\ Suresh Kumar Nayudu (iD) ${ }^{1,2}$ \\ 'Division of Gastroenterology, \\ BronxCare Hospital Center, Clinical \\ Affiliate of Mt Sinai Health Systems and \\ Academic Affiliate of Icahn School of \\ Medicine, Bronx, NY, I0457, USA; \\ ${ }^{2}$ Department of Medicine, BronxCare \\ Hospital Center, Clinical Affiliate of Mt \\ Sinai Health Systems and Academic \\ Affiliate of Icahn School of Medicine, \\ Bronx, NY, 10457, USA
}

Background: Patients requiring hospitalization to critical care units are at a higher risk for gastrointestinal (GI) bleeding. Although severe acute respiratory syndrome coronavirus 2 (SARS-COV-2) infection is predominantly a pulmonary disease, other serious manifestations including thromboembolic phenomenon are reported. Acute respiratory distress syndrome (ARDS) requiring mechanical ventilation, use of steroids and anticoagulation are all known to increase the risk of GI bleeding significantly.

Aim: To study the incidence of GI bleeding and its impact on mortality in patients admitted with SARS-CoV-2.

Methods: We retrospectively reviewed all patients admitted with SARS-CoV-2 from February 1, 2020 to April 15, 2020. We collected data including demographics, comorbid conditions, laboratory parameters, steroid and anticoagulant use. Coffee ground emesis, hematemesis, melena and hematochezia were defined as GI bleeding. All-cause mortality was reviewed for all patients included in the study. The relationship between GI bleeding and mortality was studied using logistic regression.

Results: We had a total of 1206 patients hospitalized with SARS-CoV-2 infection with an all-cause mortality of $34 \%(n=411)$. The overall incidence of GI bleeding was $3.1 \%(n=37)$ with no significant difference between the patients who survived versus died during hospitalization $(1.3 \%$ vs $1.5 \%, \mathrm{p}=0.77)$. Logistic regression analysis did not identify GI bleeding as an independent predictor of mortality. Therapeutic doses of anticoagulation were administered in $13.3 \%(n=161)$ of patients, of which $6.8 \%(n=11)$ developed GI bleeding. Patients were more likely to develop GI bleeding with use of therapeutic doses of anticoagulation $(29.7 \%$ vs $12.8 \%, \mathrm{p}=0.003)$, steroids $(37.8 \%$ vs $18.5 \%, \mathrm{p}=0.003)$ and mechanical ventilation $(48.6 \%$ vs $30.4 \%, \mathrm{p}=0.018)$.

Conclusion: Patients hospitalized with SARS-CoV-2 infection are at risk of gastrointestinal bleeding. Therapeutic doses of anticoagulation, mechanical ventilation and steroid use are significant risk factors for GI bleeding. However, GI bleeding did not significantly alter the mortality rates in SARS-CoV-2-infected patients.

Keywords: SARS-CoV-2, COVID-19, gastrointestinal bleeding, anticoagulation, coffee ground emesis

\section{Introduction}

The outbreak of novel coronavirus 2019 (COVID-19) disease caused by severe acute respiratory distress syndrome coronavirus 2 (SARS-CoV-2) has spread worldwide. In March 2020, the World Health organization (WHO) declared the COVID19 infection as a pandemic. ${ }^{1}$ SARS-CoV-2 infection, with a predominantly 
pulmonary presentation, has a wide array of manifestations ranging from asymptomatic or flu-like symptoms to severe viral pneumonia-induced respiratory distress syndrome. ${ }^{2}$ The cytopathic effects of SARS-CoV-2 on airway epithelial cells and the subsequent cytokine surge have been associated with progression to critical disease. ${ }^{3,4}$ Due to the unprecedented nature of the disease, guidelines have been rapidly evolving based on the latest available evidence. Further insight into the disease gave us knowledge about the SARS-CoV-2-induced coagulopathy and subsequent thrombosis. ${ }^{5}$ Altered coagulation profiles were noted in approximately $50 \%$ of patients with severe infection, who eventually developed thromboembolic diseases. ${ }^{6}$ As a result, guidelines favoring the use of antithrombotic agents, both at prophylactic and therapeutic doses, in patients with SARS-CoV-2 infection have emerged.

Gastrointestinal (GI) bleeding is a well-recognized morbidity in critically ill patients. ${ }^{7}$ Corticosteroid use is associated with an increased risk of GI bleeding, especially among those hospitalized. ${ }^{8}$ Mechanical ventilation, abnormal coagulation profiles and the use of antithrombotic agents are well-established risk factors for GI bleeding in critically ill patients, ${ }^{9,10}$ however, GI bleeding in critically ill patients has not been associated with an increase in mortality. ${ }^{10}$

The incidence of GI bleeding has been reported to be $0.5 \%$ in non-critical COVID-19 hospitalized patients. ${ }^{11}$ A case-matched control study did not observe any difference in the severity of COVID-19 manifestations among patients with or without GI bleeding. ${ }^{12}$ Anticoagulation has been proposed as a treatment for severe COVID-19 pneumonia, but it carries a risk of increased GI bleeding. The implications of this increased risk on in-hospital mortality are unknown. In our retrospective cohort study, we studied the incidence of GI bleeding in patients admitted with COVID-19 and investigated whether GI bleeding is an independent risk factor for SARS-CoV-2-associated mortality.

\section{Methods}

This is a retrospective cohort study approved by the Institution Review Board (IRB) of Bronx Care Health System. The study was performed as per the Declaration of Helsinki. Patient consent was not required by the IRB owing to the retrospective nature of the study, and patient data confidentiality was maintained at each and every step of the study.

\section{Patient Selection}

We included patients admitted from 1st February to 15th April 2020 with SARS-CoV-2 infection confirmed by positive polymerase chain reaction (PCR) testing of the nasopharyngeal swab specimen. Patients were followed until June 1, 2020 to review their mortality status. We excluded patients with the "Do Not Resuscitate" status in place. Demographic data such as age, gender and ethnicity were extracted from the electronic medical records (EMR). We obtained data on the following comorbid medical conditions: hypertension, diabetes mellitus, human immunodeficiency virus infection (HIV), hepatitis B infection, hepatitis $\mathrm{C}$ infection, liver cirrhosis, congestive heart failure and chronic kidney disease.

\section{GI Bleeding}

We reviewed EMR to identify COVID-19-infected patients who had overt GI during their hospitalization. Only those patients with overt manifestations of bleeding in the form of coffee ground emesis, hematemesis, melena or rectal bleeding were classified as having GI bleeding. Major GI bleeding was defined as requiring transfusion of more than two units of packed red blood cells or a decrease in hemoglobin by $2 \mathrm{~g} / \mathrm{dl}$ attributed to hemorrhage.

\section{Therapeutic Intervention and Laboratory Parameters}

Documentation in the EMR was utilized to categorize anticoagulation use in therapeutic or prophylactic doses. A computerized algorithm identified physician orders for steroid administration and mechanical ventilation during hospitalization. The initial set of laboratory parameters obtained at presentation were analyzed.

\section{Statistical Analysis}

The data were analyzed using the SPSS version 19 . Continuous variables were examined with $t$-test and expressed as means and standard deviations. Pearson's Chi-square test was used to examine categorical parameters, expressed as frequencies and percentages. The relationship between GI bleeding and mortality, and other univariate analyses were studied using logistic regression.

\section{Primary Outcome}

We studied the incidence and impact of GI bleeding on SARS-CoV-2-related in-hospital mortality in our patients. 


\section{Results}

There were 1206 patients hospitalized with SARS-CoV-2 infection from 1st February to 15th April 2020. Table 1 describes the demographics, comorbidities, laboratory parameters and outcomes of all patients with and without GI bleeding.

There was no significant age difference between patients with or without GI bleeding ( $62 \pm 16$ vs $61 \pm 14$, $\mathrm{p}=0.71$ ). GI bleeding group as compared to the group without GI bleeding (Table 1) had a significantly higher number of patients who received therapeutic doses of anticoagulation $(29.7 \%$ vs $12.8 \% ; \mathrm{P}=0.003)$ as well as steroids $(37.8 \%$ vs $18.5 \% ; \mathrm{p}=0.003)$. The need for mechanical ventilation during hospitalization was higher in patients with GI bleeding (48.6\% vs 30.4\%; $\mathrm{p}=0.018$ ). There were no significant differences in the laboratory parameters between the two groups, except for a high absolute neutrophil count $(9 \pm 5$ vs $7 \pm 4 ; p<0.001)$ and prolonged prothrombin time $(22 \pm 42$ vs $14 \pm 8$; $p<0.001)$ in patients with GI bleeding. Comparison of interventions

Table I Comparison of Baseline Demographics, Laboratory Parameters and Comorbid Conditions Between Patients with and without Gl Bleeding

\begin{tabular}{|c|c|c|c|c|}
\hline Variables & & $\begin{array}{l}\text { Gastrointestinal Bleeding } \\
\text { Present } \mathbf{N}=37(3.1 \%)\end{array}$ & $\begin{array}{l}\text { Gastrointestinal Bleeding Absent } \\
\mathbf{N}=1 / 69(96.8 \%)\end{array}$ & $P$ value \\
\hline Age (years) & & $61( \pm 14)$ & $62( \pm 16)$ & 0.71 \\
\hline Gender & Male & 27 (73\%) & $705(60.3 \%)$ & 0.121 \\
\hline Mortality & & $16(43.2 \%)$ & $395(33.8 \%)$ & 0.233 \\
\hline Length of stay (days) & & $6.5( \pm 6.3)$ & $6.7( \pm 6.3)$ & 0.83 \\
\hline Mechanical Ventilation & & 18 (48.6\%) & $355(30.4 \%)$ & 0.018 \\
\hline $\begin{array}{l}\text { Therapeutic dose of } \\
\text { anticoagulation }\end{array}$ & & II (29.7\%) & $150(12.8 \%)$ & 0.003 \\
\hline Steroid use & & 14 (37.8\%) & $216(18.5 \%)$ & 0.003 \\
\hline Laboratory parameter* & $\begin{array}{l}\text { Absolute neutrophil } \\
\text { Count }(\mathrm{k} / \mathrm{hL}) \\
\text { D-Dimer }(\mathrm{ng} / \mathrm{mL}) \\
\text { Lactate dehydrogenase } \\
(\mathrm{LDH})(\mathrm{u} / \mathrm{L}) \\
\text { CRP }(\mathrm{u} / \mathrm{L}) \\
\text { Ferritin }(\mathrm{ng} / \mathrm{mL}) \\
\text { Prothrombin time }(\mathrm{sec}) \\
\text { Hemoglobin }(\mathrm{g} / \mathrm{dL}) \\
\text { Platelet count }(\mathrm{K} / \mathrm{dL})\end{array}$ & $\begin{array}{l}9( \pm 5) \\
1034(1704) \\
575( \pm 353) \\
22( \pm 42) \\
924(1381) \\
13(3) \\
12( \pm 3) \\
236( \pm 143)\end{array}$ & $\begin{array}{l}7( \pm 4) \\
548(1061) \\
585( \pm 395) \\
14( \pm 8) \\
735( \pm 1044) \\
13(2) \\
12( \pm 2) \\
220( \pm 101)\end{array}$ & $\begin{array}{l}<0.001 \\
0.468 \\
0.882 \\
\\
0.189 \\
0.683 \\
0.636 \\
0.06 \\
0.375\end{array}$ \\
\hline $\begin{array}{l}\text { Comorbid medical } \\
\text { conditions }\end{array}$ & $\begin{array}{l}\text { Hypertension } \\
\text { Diabetes mellitus } \\
\text { HIV } \\
\text { Asthma } \\
\text { COPD } \\
\text { Hepatitis B } \\
\text { Hepatitis C } \\
\text { Liver cirrhosis } \\
\text { CHF } \\
\text { CKD }\end{array}$ & $\begin{array}{l}22(62.9 \%) \\
27(75 \%) \\
3(8.6 \%) \\
6(17.6 \%) \\
5(14.3 \%) \\
0 \\
4(10.8 \%) \\
0 \\
3(8.6 \%) \\
4(11.4 \%)\end{array}$ & $\begin{array}{l}710(61.3 \%) \\
521(45 \%) \\
76(6.6 \%) \\
148(12.8 \%) \\
113(9.8 \%) \\
4(0.3 \%) \\
48(4.1 \%) \\
12(1 \%) \\
114(9.8 \%) \\
93(8 \%)\end{array}$ & $\begin{array}{l}0.853 \\
<0.001 \\
0.638 \\
0.473 \\
0.377 \\
0.728 \\
0.048 \\
0.536 \\
0.803 \\
0.469\end{array}$ \\
\hline
\end{tabular}

Note: *Continuous variable represented as Median (interquartile range) and comparison is done using the Mann-Whitney U-test. 
Table 2 Comparison of Interventions Utilized Among Patients with or without Gastrointestinal Bleeding

\begin{tabular}{|l|l|l|l|}
\hline Variables & $\begin{array}{l}\text { Gastrointestinal Bleeding Present } \\
\text { N = 37 (3.1\%) }\end{array}$ & $\begin{array}{l}\text { Gastrointestinal Bleeding Absent N = } \\
\text { I l69 (96.8\%) }\end{array}$ & P value \\
\hline Mechanical Ventilation & $18(48.6 \%)$ & $355(30.4 \%)$ & 0.018 \\
Prophylactic doses of anticoagulation & $9(34.6 \%)$ & $579(56.8 \%)$ & $150(12.8 \%)$ \\
Therapeutic doses of anticoagulation & $11(29.7 \%)$ & $445(38.1 \%)$ & 0.024 \\
Low molecular weight heparin & $12(32.4 \%)$ & $2(0.2 \%)$ & 0.003 \\
Therapeutic doses of heparin & $1(2.7 \%)$ & $10(0.9 \%)$ & 0.487 \\
Warfarin & 0 & $53(4.5 \%)$ & 0.002 \\
Novel oral anticoagulant use & $4(11.1 \%)$ & $216(18.5 \%)$ & 0.572 \\
Steroid use & $14(37.8 \%)$ & $735(62.9 \%)$ & 067 \\
Proton pump inhibitor plus H2-blocker & $34(91.9 \%)$ & $62(5.3 \%)$ & 0.003 \\
Tocilizumab & $2(5.4 \%)$ & $2(0.2 \%)$ & $13(1.1 \%)$ \\
Anti-Viral medications & 0 & 0.001 \\
Convalescent Plasma & 0 & 0.538 \\
\hline
\end{tabular}

utilized among patients with or without gastrointestinal bleeding is given in Table 2 .

The mean age of patients who expired was higher than those who survived ( $68 \pm 12$ vs $59 \pm 16, \mathrm{p}<0.005)$. There was a higher incidence of GI bleeding in patients who died (3.9\%) versus those who survived $(2.6 \%)$; however, this difference was not statistically significant $(\mathrm{P}=0.233)$ (Table 3). Upper GI bleeding, particularly coffee ground emesis, was the most common presentation of GI bleeding $(n=30,81 \%)$. Forty-three percent of patients $(n=16)$ were considered to have major GI bleeding. Neither the presence of major GI bleeding nor the source of bleeding (upper, lower, or combined) was different among the groups with or without mortality (Table 3 ). The use of therapeutic doses of anticoagulation $(\mathrm{p}=<0.001)$, steroids $(\mathrm{p}=0.002)$, and mechanical ventilation $(\mathrm{p}=<0.001)$ was significantly higher in patients with mortality. Two of 37 patients with GI bleeding underwent esophagogastroduodenoscopy and had gastric and jejunal ulcers requiring therapeutic intervention.

Multivariate logistic regression was performed to identify and study the independent predictors of mortality and their association with GI bleeding (Table 4). GI bleeding has not been identified as an independent predictor of mortality (p 0.84).

\section{Discussion}

Patients hospitalized with COVID-19 who developed GI bleeding during the hospitalization in comparison to those

Table 3 Demographics, GI Bleeding and Management Between SARS-CoV-2 Patients Who Had Mortality vs No Morality During Hospitalization

\begin{tabular}{|c|c|c|c|c|}
\hline Variables & & No Mortality N = 795 (66\%) & Mortality N = $4 \mid 2(34 \%)$ & p-value \\
\hline Age in years- mean $( \pm S D)$ & & $59( \pm 16)$ & $68( \pm 12)$ & $<0.005$ \\
\hline Gender & Male & $454(57 \%)$ & $279(67.7 \%)$ & $<0.005$ \\
\hline Gastrointestinal bleeding & & $21(2.6 \%)$ & 16 (3.9\%) & 0.233 \\
\hline Major gastrointestinal bleeding & & $10(1.3 \%)$ & $6(1.5 \%)$ & 0.772 \\
\hline Bleeding source & $\begin{array}{l}\text { Upper GI source } \\
\text { Lower Gl source } \\
\text { Upper and Lower Gl source }\end{array}$ & $\begin{array}{l}18(2.3 \%) \\
2(0.3 \%) \\
1(0.1 \%)\end{array}$ & $\begin{array}{l}12(2.9 \%) \\
4(1 \%) \\
0\end{array}$ & 0.209 \\
\hline Therapeutic anticoagulation & & $84(10.6 \%)$ & $77(18.7 \%)$ & $<0.001$ \\
\hline Steroid use & & $132(16.6 \%)$ & $98(23.8 \%)$ & 0.002 \\
\hline Mechanical ventilation & & 77 (9.7\%) & 407 (99\%) & $<0.001$ \\
\hline
\end{tabular}


Table 4 Multivariate Logistic Regression for Mortality Predictors

\begin{tabular}{|c|c|c|}
\hline Variable & Odds Ratio & p-value \\
\hline Gastrointestinal (GI) bleeding & $0.89(0.31$ to 2.59$)$ & 0.84 \\
\hline Hypertension & $0.76(0.48$ to 1.20$)$ & 0.24 \\
\hline Diabetes mellitus & $1.10(0.72$ to 1.68$)$ & 0.67 \\
\hline HIV & $0.54(0.24$ to 1.23$)$ & 0.14 \\
\hline COPD & $0.48(0.24$ to 0.97$)$ & 0.04 \\
\hline Chronic Kidney Disease & 2.06 (0.98 to 4.31$)$ & 0.06 \\
\hline Congestive Heart Failure & 1.98 (0.99 to 3.95$)$ & 0.05 \\
\hline Hepatitis C & $0.28(0.1 \mathrm{I}$ to 0.75$)$ & 0.01 \\
\hline Lactate dehydrogenase (LDH) & $1.00(1.00$ to 1.00$)$ & $<0.001$ \\
\hline D-Dimer increase & $1.00(1.00$ to 1.00$)$ & $<0.001$ \\
\hline C Reactive protein increase & $1.01(1.00$ to 1.01$)$ & $<0.001$ \\
\hline $\begin{array}{l}\text { Therapeutic doses of } \\
\text { anticoagulation present }\end{array}$ & $1.05(0.59$ to 1.86$)$ & 0.86 \\
\hline Steroid administration present & I.89 (I.II to 3.22$)$ & 0.02 \\
\hline Mechanical ventilation present & $26.17(15.8 I$ to 43.31$)$ & $<0.001$ \\
\hline
\end{tabular}

who did not develop GI bleeding, had significantly higher use of steroids, therapeutic doses of anticoagulation and mechanical ventilation. However, GI bleeding itself did not predict higher mortality in these patients. Even after adjusting for established risk factors for in-hospital mortality such as the need for mechanical ventilation, corticosteroid use, and gastrointestinal bleeding, this was not associated with a significantly increased risk of in-hospital mortality.

The incidence of GI bleeding in intensive care units (ICU) varies from $1.5 \%$ to $5.5 \%{ }^{13,14}$ Institutional differences in the ICU evaluation criteria may be attributed to this varying incidence. In our study, $3.1 \%$ of the COVID19 patients had GI bleeding during hospitalization. This is higher than the incidence of GI bleeding in non-Covid hospitalized patients, which can range from $0.005 \%$ to $0.4 \% .^{15,16}$ The surge in COVID-19 cases during the pandemic altered ICU triage parameters and many critically ill patients were managed in modified units. Hence, to capture all these patients who were critically ill but managed outside of ICU setting, we analyzed GI bleeding for all patients hospitalized with COVID-19. Due to the risk of COVID-19 spread from oropharyngeal secretions during endoscopy ${ }^{17}$ most of the patients with GI bleeding were managed conservatively.

Consistent with existing COVID-19 literature, ${ }^{18}$ our data showed that patients who succumbed to COVID-19 were older and had significantly more comorbid conditions, such as hypertension, diabetes mellitus, chronic obstructive pulmonary disease and chronic kidney disease. Serum biomarkers, such as lactate dehydrogenase,
C-reactive protein and lymphocyte count, have been previously shown to predict worse outcomes in patients with COVID-19. ${ }^{19}$ Our study results further strengthen the data on these laboratory indicators of COVID-19 infection severity. Elevated levels of neutrophils, D dimer, $\mathrm{C}$ reactive protein, and ferritin, as well as lower levels of serum albumin predicted worse outcomes. The requirement of mechanical ventilation in patients with COVID19 is a known risk factor for increased mortality. ${ }^{20}$

Corticosteroids have been an integral part of COVID19 infected patient management. A meta-analysis from 7 randomized controlled trial has shown steroids to be beneficial in decreasing mortality in critically ill COVID-19 patients. ${ }^{21}$ However, steroids are generally administered to patients with severe COVID-19 disease, and hence they are more likely to have worse outcomes. In our study population, corticosteroids were administered in patients with severe pulmonary disease. These patients, due to the inherent disease severity, were more likely to have higher mortality rates than those who did not receive corticosteroids $(23.8 \%$ vs $16.6 \%$, p 0.002$)$.

A high incidence of thromboembolic events among patients with COVID-19 has been reported. ${ }^{22}$ Some studies showed increased survival benefits among these patients with the use of anticoagulation. ${ }^{23}$ A systematic review of 4 studies evaluating the impact of anticoagulation on COVID-19 patient outcomes found decreased mortality in these patients with the use of therapeutic doses of anticoagulation. ${ }^{24}$ However, the risk of increased bleeding due to anticoagulation must be weighed against the benefits. Oral anticoagulants carry a $13.4 \%$ case fatality rate for major bleeds. ${ }^{25}$ In our study, we found a significantly higher number of patients with GI bleeding being managed with therapeutic doses of anticoagulation $(29.7 \%$ vs $12.8 \%, \mathrm{p} 0.003)$. These patients receiving therapeutic doses of anticoagulation had more severe COVID-19 manifestations, carrying a higher mortality rate. However, for the patients who did not survive while on anticoagulation, there was no significant difference between those who had GI bleeding versus those who did not have GI bleeding ( $48 \%$ vs $45.5 \%, \mathrm{p}$ 0.871). We observed a higher use of proton pump inhibitors (PPI) and histamine-2 (H2) receptor blockers among patients with GI bleeding. The use of these agents reflects both treatment and prevention of GI bleeding.

Patients who received steroids, therapeutic anticoagulation and required mechanical ventilation had higher mortality in our study population, and the same risk factors 
were associated with increased risk of GI bleeding during the hospitalization. ${ }^{9,10}$ However, as previously discussed, GI bleeding did not increase mortality in patients with critical illness. ${ }^{10}$ We performed multi-variate regression and controlled for predictors of mortality to evaluate if GI bleeding is an independent predictor of mortality in patient with COVID-19. There was no significant difference in the occurrence of major GI bleeding amongst patients who survived versus those who died $(1.3 \%$ vs $1.5 \%, \mathrm{p}=0772$ ). As noted in other critical illnesses, the presence of GI bleeding did not increase mortality in our study patient group. The overall number of patients who had GI bleeding in our study is small and hence larger studies are needed to validate these results.

Limitations of our study are retrospective nature and single-center design. We do not have information about patient's prior history of peptic ulcers, which might have put them at a higher risk of GI bleeding. We also lack information about Charleston comorbidity index, instead we include a comparison of different comorbid conditions between the two groups. The laboratory values used in our study were obtained from the time of admission, and we did not take into account the change in these dynamic variables throughout the hospital stay. Moreover, due to lack of endoscopic findings in most of our patients, we were unable to confirm the etiology of GI bleeding. Our objective was to evaluate the prognostic impact of GI bleeding on mortality in COVID-19 disease. Based on our study design, it is difficult to draw conclusions about management strategies: conservative vs endoscopic management of GI bleeding. In our study, there were 2 patients who required endoscopy for management of GI bleeding. The retrospective review from Italy, which included follow-up of 23 patients with GI bleeding amongst a cohort of 4871 COVID-19 patients, did not show any difference in mortality amongst patient who had endoscopy in 24 hours.

\section{Conclusion}

Our study reiterates the higher mortality in COVID-19 infected older patients with multiple comorbid conditions. Use of anti-coagulants, steroids and mechanical ventilation were statistically more frequent in the GI bleeding group. However, GI bleeding did not predict a worse outcome or mortality in COVID-19 patients.

\section{Author Contributions}

All authors made a significant contribution to the work reported, whether that is in the conception, study design, execution, acquisition of data, analysis and interpretation, or in all these areas; took part in drafting, revising or critically reviewing the article; gave final approval of the version to be published; have agreed on the journal to which the article has been submitted; and agree to be accountable for all aspects of the work.

\section{Disclosure}

The authors report no conflicts of interest in this work.

\section{References}

1. WHO. WHO director-general's opening remarks at the media briefing on COVID-19-11 March 2020. Available from: https:// wwwwhoint/dg/speeches/detail/who-director-general-s-openingremarks-at-the-media-briefing-on-covid-19-11-march-2020. Accessed September 29, 2021.

2. Guan W-J, Ni Z-Y, Hu Y, et al. Clinical characteristics of coronavirus disease 2019 in China. $N$ Engl J Med. 2020;382(18):1708-1720. doi:10.1056/NEJMoa2002032

3. Tang Y, Liu J, Zhang D, Xu Z, Ji J, Wen C. Cytokine storm in COVID-19: the current evidence and treatment strategies. Front Immunol. 2020;11:1708. doi:10.3389/fimmu.2020.01708

4. Zhu N, Wang W, Liu Z, et al. Morphogenesis and cytopathic effect of SARS-CoV-2 infection in human airway epithelial cells. Nat Commun. 2020;11(1):3910. doi:10.1038/s41467-020-17796-Z

5. Miesbach W, Makris M. COVID-19: coagulopathy, risk of thrombosis, and the rationale for anticoagulation. Clin Appl Thromb Hemost. 2020;26:1076029620938149. doi:10.1177/1076029620938149

6. Klok FA, Kruip M, van der Meer NJM, et al. Confirmation of the high cumulative incidence of thrombotic complications in critically ill ICU patients with COVID-19: an updated analysis. Thromb Res. 2020;191:148-150. doi:10.1016/j.thromres.2020.04.041

7. Kumar S, Ramos C, Garcia-Carrasquillo RJ, Green PH, Lebwohl B. Incidence and risk factors for gastrointestinal bleeding among patients admitted to medical intensive care units. Frontline Gastroenterol. 2017;8(3):167-173. doi:10.1136/flgastro-2016-100722

8. Narum S, Westergren T, Klemp M. Corticosteroids and risk of gastrointestinal bleeding: a systematic review and meta-analysis. $B M J$ Open. 2014;4(5):e004587. doi:10.1136/bmjopen-2013-004587

9. Ye Z, Reintam Blaser A, Lytvyn L, et al. Gastrointestinal bleeding prophylaxis for critically ill patients: a clinical practice guideline. BMJ. 2020;368:16722. doi:10.1136/bmj.16722

10. Krag M, Perner A, Wetterslev J, et al. Prevalence and outcome of gastrointestinal bleeding and use of acid suppressants in acutely ill adult intensive care patients. Intensive Care Med. 2015;41 (5):833-845. doi:10.1007/s00134-015-3725-1

11. Mauro A, De Grazia F, Lenti MV, et al. Upper gastrointestinal bleeding in COVID-19 inpatients: incidence and management in a multicenter experience from Northern Italy. Clin Res Hepatol Gastroenterol. 2021;45(3):101521. doi:10.1016/j.clinre.2020.07.025

12. Martin TA, Wan DW, Hajifathalian K, et al. Gastrointestinal bleeding in patients with coronavirus disease 2019: a Matched Case-Control Study. Am J Gastroenterol. 2020;115(10):1609-1616. doi:10.14309/ ajg.0000000000000805

13. Cook DJ, Fuller HD, Guyatt GH, et al. Risk factors for gastrointestinal bleeding in critically ill patients. $N$ Engl J Med. 1994;330 (6):377-381. doi:10.1056/NEJM199402103300601

14. Alhazzani W, Guyatt G, Alshahrani M, et al. Withholding pantoprazole for stress ulcer prophylaxis in critically ill patients: a pilot randomized clinical trial and meta-analysis. Crit Care Med. 2017;45 (7):1121-1129. doi:10.1097/CCM.0000000000002461 
15. Terdiman JP, Ostroff JW. Gastrointestinal bleeding in the hospitalized patient: a Case-Control Study to assess risk factors, causes, and outcome. Am J Med. 1998;104(4):349-354. doi:10.1016/S0002-9343(98)00055-2

16. Qadeer MA, Richter JE, Brotman DJ. Hospital-acquired gastrointestinal bleeding outside the critical care unit: risk factors, role of acid suppression, and endoscopy findings. J Hosp Med. 2006;1:13-20. doi: $10.1002 / \mathrm{jhm} .10$

17. Perisetti A, Gajendran M, Boregowda U, Bansal P, Goyal H. COVID19 and gastrointestinal endoscopies: current insights and emergen strategies. Dig Endosc. 2020;32(5):715-722. doi:10.1111/den.13693

18. Chen Q, Zheng Z, Zhang C, et al. Clinical characteristics of 145 patients with Corona virus disease 2019 (COVID-19) in Taizhou, Zhejiang, China. Infection. 2020;48(4):543-551. doi:10.1007/ s15010-020-01432-5

19. Gallo Marin B, Aghagoli G, Lavine K, et al. Predictors of COVID-19 severity: a literature review. Rev Med Virol. 2021;31(1):1-10.

20. Nicholson CJ, Wooster L, Sigurslid HH, et al. Estimating risk of mechanical ventilation and in-hospital mortality among adult COVID-19 patients admitted to mass general Brigham: the VICE and DICE scores. EClinicalMedicine. 2021;33:100765. doi:10.1016/ j.eclinm.2021.100765
21. Group TWREAfC-TW. Association between administration of systemic corticosteroids and mortality among critically ill patients with COVID-19: a meta-analysis. JAMA. 2020;324(13):1330-1341. doi:10.1001/jama.2020.17023

22. Kollias A, Kyriakoulis KG, Dimakakos E, Poulakou G, Stergiou GS, Syrigos K. Thromboembolic risk and anticoagulant therapy in COVID-19 patients: emerging evidence and call for action. $\mathrm{Br}$ J Haematol. 2020;189(5):846-847. doi:10.1111/bjh.16727

23. Paranjpe I, Fuster V, Lala A, et al. Association of treatment dose anticoagulation with in-hospital survival among hospitalized patients with COVID-19. J Am Coll Cardiol. 2020;76(1):122-124. doi:10.1016/j.jacc.2020.05.001

24. Lazaridis D, Leung S, Kohler L, Smith CH, Kearson ML, Eraikhuemen N. The impact of anticoagulation on COVID-19 (SARS CoV-2) patient outcomes: a systematic review. J Pharm Pract. 2021;8971900211015055. doi:10.1177/08971900211015055

25. Linkins LA, Choi PT, Douketis JD. Clinical impact of bleeding in patients taking oral anticoagulant therapy for venous thromboembolism: a meta-analysis. Ann Intern Med. 2003;139(11):893-900. doi:10.7326/0003-4819-139-11-200312020-00007

\section{Publish your work in this journal}

Clinical and Experimental Gastroenterology is an international, peerreviewed, open access, online journal publishing original research, reports, editorials, reviews and commentaries on all aspects of gastroenterology in the clinic and laboratory. This journal is indexed on American Chemical Society's Chemical Abstracts Service (CAS)
The manuscript management system is completely online and includes a very quick and fair peer-review system, which is all easy to use. Visit http://www.dovepress.com/testimonials.php to read real quotes from published authors. 